\title{
Expressão imuno-histoquímica de proteínas da matriz extracelular em cistos odontogênicos calcificantes
}

Primeira submissão em 02/09/03 Ultima submissão em 19/03/04 Aceito para publicação em 16/04/04 Publicado em 20/10/04

\author{
Immunohistochemical expression of extracellular matrix proteins in calcifying odontogenic cyst
}

Rosilene Calazans Soares'; Márcia Cristina da Costa Miguel'; Roseana de Almeida Freitas²; Hébel Cavalcanti Galvão²; Lélia Batista de Souza²

\begin{tabular}{|c|c|}
\hline un & uno \\
\hline $\begin{array}{l}\text { Cisto odontogênico } \\
\text { calcificante } \\
\text { Matriz extracelular } \\
\text { Ossos maxilares }\end{array}$ & $\begin{array}{l}\text { Introdução: O cisto odontogênico calcificante (COC) é uma lesão odontogênica de natureza benigna } \\
\text { considerada por alguns autores como uma lesão exclusivamente cística, enquanto outros admitem uma } \\
\text { contraparte neoplásica benigna. Vários estudos têm pesquisado a natureza das células fantasmas carac- } \\
\text { terísticas do COC, porém permanece obscuro o conhecimento sobre a expressão dos constituintes da } \\
\text { matriz extracelular (MEC) nessa lesão. Objetivo: Realizar uma avaliação imuno-histoquímica da expressão } \\
\text { de proteínas constituintes da MEC (fibronectina, tenascina e colágeno I) em espécimes de COCs, a fim } \\
\text { de verificar se há diferenças significativas em tal expressão ou se esses padrões representam um espectro } \\
\text { da mesma entidade. Material e métodos: Foram utilizados dez casos de COCs, representados por cinco } \\
\text { do tipo unicístico simples, três do tipo produtor de odontoma e dois com proliferação ameloblastoma- } \\
\text { tosa, que foram submetidos à técnica imuno-histoquímica da estreptoavidina-biotina com anticorpos } \\
\text { monoclonais anti-fibronectina, anti-tenascina e anti-colágeno I. Resultados: Verificou-se que houve uma } \\
\text { expressão variável das proteínas pesquisadas, tanto entre as lesões do mesmo grupo, como entre os } \\
\text { três grupos estudados, sendo notável a reatividade para os três anticorpos apresentada pelas células } \\
\text { fantasmas. Conclusão: Não foi possível observar um padrão de marcação que denotasse diferenças } \\
\text { entre o tipo unicístico simples, o produtor de odontoma e o com proliferação ameloblastomatosa. Esse } \\
\text { achado reforça a visão de que os vários tipos histológicos do COC podem, simplesmente, representar } \\
\text { espectros histológicos diferentes de uma só entidade com comportamento biológico semelhante. }\end{array}$ \\
\hline
\end{tabular}

abstract

Background: The calcifying odontogenic cyst (COC) is an odontogenic lesion of benign nature considered by some authors as an exclusively cystic lesion, while others admit a benign neoplastic counterpart. Some studies have studied the nature of the characteristic ghost cells of the COC. However, the understanding of the expression of the extracellular matrix (MEC) components in this lesion remains unclear. Objective: To carry out an immunohistochemical evaluation of the expression of some proteins of the MEC in specimens of COCs, in order to verify wheather there are significant differences in this expression, or these patterns represent a spectrum of the same entity. Methods: Ten cases of COCs were selected, representing the following diagnosis: Five cases of simple unicystic type, three odontoma producing type and two with ameloblastomatous proliferating type. The specimens were processed for immunohistochemical staining by the streptavidin-biotin method with monoclonal antibodies anti-fibronectin, tenascin and collagen I. Results: A variable expression of the proteins studied was verified, not only in the lesions of the same group, but also among the three studied groups. There was a notable reactivity for the three antibodies in ghost cells. Conclusion: It was not possible to observe a characteristic staining profile that denoted differences between the simple unicystic type, the odontoma producing type and the ameloblastomatous proliferating type. This finding supports the concept that the histologic types of the COC might represent different specters of the same entity with similar biological behavior.

\section{key words}

Calcifying odontogenic

cyst

Extracellular matrix

Jaws 


\section{Introdução}

O cisto odontogênico calcificante (COC) é uma lesão odontogênica que foi caracterizada como uma entidade distinta, em 1962, por Gorlin, sendo considerada de natureza benigna ${ }^{(26)}$ e derivada de remanescentes do epitélio odontogênico dentro dos ossos maxilares ou da gengiva ${ }^{(15)}$.

Alguns investigadores consideram o COC uma lesão exclusivamente cística, porque em alguns casos ele se apresenta como uma cavidade patológica revestida por epitélio, contendo material fluido ou semi-sólido. Entretanto, outros autores acreditam que exista uma contraparte neoplásica benigna do COC, em função do fato de algumas dessas lesões não serem císticas e apresentarem um comportamento localmente destrutivo e agressivo(15).

O COC é um cisto de desenvolvimento que pode apresentar recidiva e ocorre de forma intra ou extra-óssea, sendo a primeira a forma mais comum ${ }^{(33)}$. Há predileção pelo sexo feminino e pela maxila ${ }^{(22)}$. O COC central é encontrado mais comumente na segunda década de vida (mais de $40 \%$ dos casos), enquanto que o COC periférico afeta indivíduos mais comumente na sexta década ${ }^{(20)}$.

Radiograficamente, o COC não tem aspectos característicos. O cisto intra-ósseo é uma lesão essencialmente destrutiva, produzindo uma imagem radiolúcida unilocular ou multilocular que pode conter áreas radiopacas irregulares. As placas corticais de osso são freqüentemente finas $\mathrm{e}$ expandidas, podendo se tornar perfuradas pela lesão, que usualmente causa deslocamento e reabsorção do dente adjacente. As lesões extra-ósseas podem causar erosão superficial do osso subjacente ${ }^{(15)}$.

As características histopatológicas incluem um revestimento epitelial constituído por células basais que variam de cuboidais a colunares, semelhantes a ameloblastos e células das camadas mais superficiais arranjadas mais frouxamente, lembrando o retículo estrelado do órgão do esmalte. Quantidades variáveis de células epiteliais sem núcleo, levemente eosinofílicas, denominadas células fantasmas, representam um importante aspecto microscópico dessa lesão(9). Entretanto, a presença dessas células não é patognomônica, tendo sido descrita também em ameloblastoma, fibroma ameloblástico, fibrodontoma ameloblástico e odontomas ${ }^{(20,22)}$. Outras características observadas incluem a calcificação das células fantasmas e a presença de dentina displásica, que pode estar localizada perto da camada basal do epitélio. Em algumas instâncias, o cisto está associado a uma área mais extensa de formação de tecido duro dentário, que se assemelha àquela de um odontoma composto ou complexo ${ }^{(15)}$.
Proteínas constituintes do esmalte dentário, como amelogenina e enamelina, foram pesquisadas nos COCs por vários autores ${ }^{(1,24,30,36)}$. Outros investigaram, ainda, a atividade proliferativa dessas lesões ${ }^{(30,32,36)}$. Entretanto, permanece obscuro o conhecimento sobre a expressão dos constituintes da matriz extracelular (MEC) no $\mathrm{COC}$, sendo relatada apenas a expressão da tenascina $\mathrm{C}$ em três casos de COC, por Lukinmaa et al..$^{(13)}$.

Frente ao exposto, a proposta deste estudo foi comparar a imunoexpressão das proteínas constituintes da MEC, representadas pela fibronectina, pela tenascina e pelo colágeno I, em dez casos de COC com padrões histológicos distintos, objetivando verificar se há diferenças significativas em tal expressão ou se esses padrões representam um espectro da mesma entidade.

\section{Material e método}

\section{Amostra}

Foram selecionados dez casos de COC a partir dos arquivos do Serviço de Anatomia Patológica da Disciplina de Patologia Oral do Curso de Odontologia da Universidade Federal do Rio Grande do Norte (UFRN), compreendendo espécimes incluídos em blocos de parafina, representados por cinco casos do tipo unicístico simples, três do tipo produtor de odontoma e dois com proliferação ameloblastomatosa, de acordo com a classificação de Praetorius et al. ${ }^{(21)}$.

\section{Estudo imuno-histoquímico}

Para o estudo imuno-histoquímico, cortes de $3 \mu \mathrm{m}$ de espessura de cada espécime foram obtidos e montados em lâminas de vidro com adesivo à base de organossilano (3-aminopropiltrietoxisilano, Sigma Chemical Co, St. Louis, $\mathrm{MO}, \mathrm{USA}$ ). A técnica imuno-histoquímica incluiu anticorpos para algumas proteínas constituintes da MEC, como a fibronectina, a tenascina e o colágeno I. Os cortes foram desparafinizados, submetidos à recuperação antigênica e, subseqüentemente, imersos em duas passagens de peróxido de hidrogênio $\left(\mathrm{H}_{2} \mathrm{O}_{2}, 10 \mathrm{v}\right)$ de 15 minutos cada, para inativação da peroxidase endógena. Posteriormente foram incubados com anticorpos primários anti-fibronectina, anti-colágeno I e anti-tenascina, conforme especificado na Tabela. As lavagens entre as etapas foram realizadas em solução tampão Tris- $\mathrm{HCl}(\mathrm{pH} \mathrm{7,4).} \mathrm{Em} \mathrm{uma} \mathrm{fase} \mathrm{subseqüen-}$ te, os cortes foram incubados à temperatura ambiente por 15 minutos, em uma câmara úmida, com os respectivos 


\begin{tabular}{|c|c|c|c|c|c|}
\hline Tabela & \multicolumn{5}{|c|}{$\begin{array}{l}\text { Clone, especificidade, diluição, incubação e tratamento prévio dos anticorpos } \\
\text { primários utilizados }\end{array}$} \\
\hline Clone & Especificidade & Fonte & Diluição & Incubação & Recuperação antigênica \\
\hline A-245 & $\begin{array}{l}\text { Fibronectina } \\
\text { (A0245) }\end{array}$ & Dako* & $1: 500$ & $\begin{array}{c}\text { Duas horas } \\
\text { (temperatura } \\
\text { ambiente) }\end{array}$ & $\begin{array}{l}\text { Pepsina } 1 \% \text { em estufa } \\
37^{\circ} \mathrm{C} \text { durante uma hora }\end{array}$ \\
\hline TN2 & $\begin{array}{l}\text { Tenascina } \\
(\mathrm{M} 0636)\end{array}$ & Dako* & $1: 50$ & $\begin{array}{l}\text { Overnight } \\
\qquad\left(8^{\circ} \mathrm{C}\right)\end{array}$ & $\begin{array}{l}\text { Pepsina } 0,4 \% \text { em estufa } \\
37^{\circ} \mathrm{C} \text { durante } 30 \text { minutos }\end{array}$ \\
\hline PHM-12 & $\begin{array}{l}\text { Colágeno I } \\
\text { (NCL-COLL-Ip) }\end{array}$ & Novocastra** & 1:40 & $\begin{array}{c}\text { Uma hora } \\
\text { (temperatura } \\
\text { ambiente) }\end{array}$ & $\begin{array}{l}\text { Citrato em panela a vapor } \\
\text { durante cinco minutos }\end{array}$ \\
\hline
\end{tabular}

*Dako Co., Carpinteria, CA, USA; **Benton Lane, Newcastle, UK.

anticorpos secundários e o complexo estreptavidina-biotina-peroxidase (L.V. Dako LSAB ${ }^{\circledR}+$ Kit, HRP, K0690/Dako Corporation, Carpinteria, CA, USA). A diaminobenzidina a 0,03\% (Sigma Chemical Co., St. Louis, MO, USA) foi usada como cromógeno para revelação da reação. A contracoloração foi feita com hematoxilina de Mayer.

\section{Avaliação da expressão imuno-histoquímica das proteínas da MEC}

A imunomarcação das proteínas da MEC (fibronectina, tenascina e colágeno I) foi avaliada quanto a intensidade e padrão de distribuição. A intensidade de expressão de cada proteína foi graduada em forte e fraca. Quanto ao padrão de distribuição, foi considerado difuso quando se estendeu por todo o tecido conjuntivo e focal e quando se expressou apenas em determinadas áreas do espécime. Esses parâmetros foram examinados por dois observadores (RCS; MCCM) previamente treinados.

\section{Resultados}

\section{Expressão da fibronectina}

Nos cinco casos de COCs unicísticos verificou-se marcação intensa nas células fantasmas. Em quatro deles foi observada uma linha contínua e forte na interface epitélio/ conjuntivo (Figura 1), e no outro caso a linha apresentou-se fraca e descontínua. Na cápsula pôde-se notar imunomarcação de intensidade fraca em todos os COCs unicísticos, de forma difusa em quatro deles e focal próxima ao epitélio em um dos casos.

Em um dos espécimes de COCs produtores de odontoma, observou-se marcação intra-epitelial. Quanto às células fantasmas, estas exibiram intensa marcação em todos os casos. Na interface epitélio/conjuntivo verificou-se imunoexpressão sob a forma de linha contínua e forte em um dos casos, e nos demais tal fato não foi observado. Na cápsula, evidenciou-se imunorreação intensa e difusa em um dos casos, podendo-se notar marcação apenas focalmente ou de fraca intensidade nos outros dois. As áreas relativas ao tecido duro do odontoma mostraram-se negativas para fibronectina.

Apenas um dos COCs com proliferação ameloblastomatosa apresentou linha contínua delimitando área de degeneração cística no revestimento epitelial. As células fantasmas exibiram forte reatividade e, na interface epitélio/conjuntivo, evidenciou-se linha contínua nos dois casos, apresentando-se com forte intensidade em um deles.

Os vasos sangüíneos de todos os espécimes exibiram reatividade em região de membrana basal.

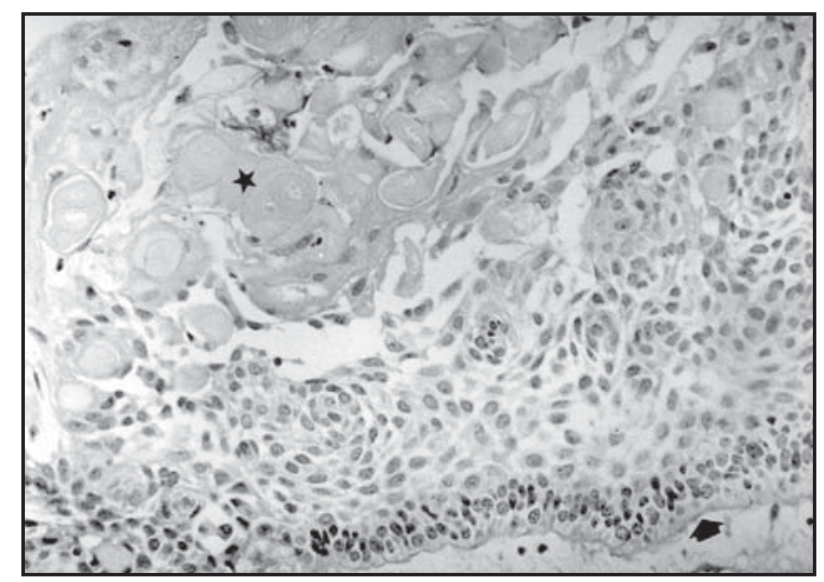

Figura 1 - Células fantasma marcadas para fibronectina (estrela). Observar também uma linha contínua e forte na interface epitélio/conjuntivo (seta) $(S A B C / 200 x)$ 


\section{Expressão da tenascina}

Em todos os cinco casos de COCs unicísticos, as células fantasmas exibiram-se ora negativas ora imunorreativas para a tenascina, sendo essa reatividade por vezes fraca, outras vezes intensa. $\mathrm{Na}$ interface epitélio/conjuntivo foi possível observar que todos os COCs unicísticos analisados exibiram marcação positiva, sendo contínua e intensa em três casos (Figura 2) e descontínua e fraca nos outros dois. A cápsula exibiu fraca reatividade em áreas focais de todos os espécimes.

Nos produtores de odontoma houve marcação intra-epitelial em apenas um dos três casos. As células fantasmas exibiram o mesmo padrão de expressão dos unicísticos. Em três casos, a interface epitélio/conjuntivo exibiu imunorreatividade focal e fraca. Notou-se, ainda, que foi exibida fraca reatividade na cápsula em um caso e, em dois, não foi observada marcação. As áreas relativas ao tecido duro do odontoma não foram imunorreativas.

A marcação intra-epitelial foi evidenciada nos dois casos com proliferação ameloblastomatosa e as células fantasmas demonstraram o mesmo padrão de expressão observado nos unicísticos. A interface epitélio/conjuntivo não exibiu reatividade, entretanto, observou-se fraca marcação na cápsula dos dois casos estudados.

\section{Expressão do colágeno I}

Em todos os cinco casos de COCs unicísticos observouse negatividade na interface epitélio/conjuntivo. As células fantasmas exibiram-se ora negativas, ora imunorreativas de fraca intensidade, sendo que em áreas onde elas se encontravam fusionadas, formando aglomerados, pôdese notar marcação mais intensa (Figura 3). Na cápsula verificou-se positividade nos cinco casos avaliados, sendo que quatro deles exibiram marcação difusa e, em apenas um caso, foi observada marcação mais intensa formando faixa subepitelial.

Nos COCs produtores de odontoma, a interface epitélio/conjuntivo e as células fantasmas exibiram expressão semelhante aos unicísticos. Uma marcação também difusa foi observada na cápsula conjuntiva de todos os casos analisados, apresentando-se forte em um deles.

A expressão do colágeno I na interface epitélio/conjuntivo e em células fantasmas, nos dois casos de COCs com proliferação ameloblastomatosa avaliados, seguiu o mesmo padrão dos unicísticos, e na cápsula houve forte imunorreatividade em um dos casos.

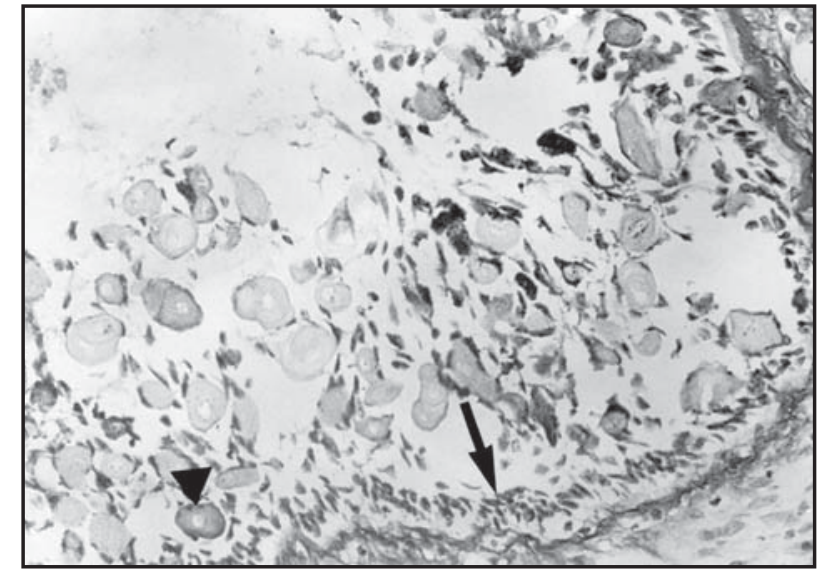

Figura 2 - Expressão focal da tenascina nas células fantasma (cabeça de seta). Observar disposição das células em paliçada da camada basal epitelial do COC (seta) $(S A B C / 200 x)$

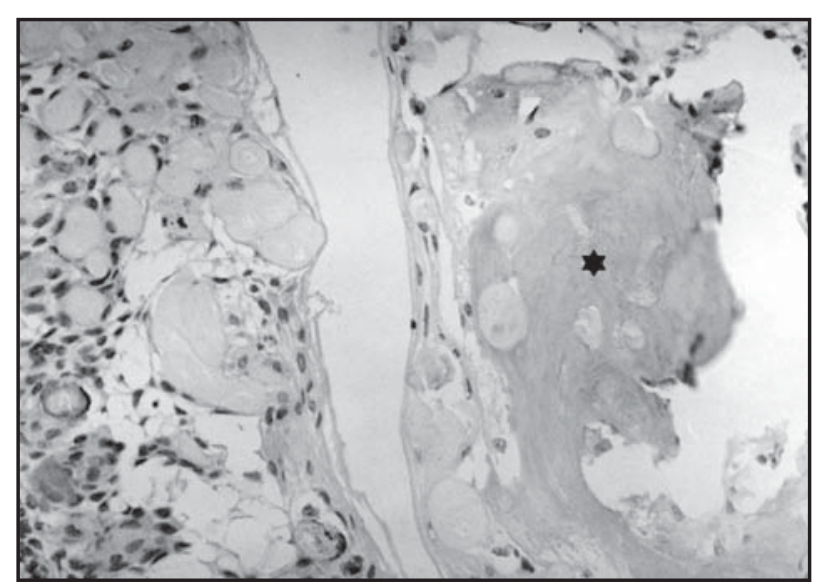

Figura 3 - Expressão mais intensa do colágeno I nas células fantasma fusionadas (estrela) $(S A B C / 200 x)$

\section{Discussão}

Em função das diversidades clínica, histopatológica e de comportamento biológico, há controvérsias em relação à classificação e à terminologia do COC. As tentativas para sua classificação podem ser baseadas em um conceito monístico, no qual todos os COCs têm natureza neoplásica, em que se enquadra a classificação da Organização Mundial da Saúde (OMS) (1992), comentada por Kramer et al. ${ }^{(10)}$. Podem também se fundamentar em um conceito dualístico em que o COC é dividido em duas entidades: uma cística e uma neoplásica ${ }^{(33)}$. Baseando-se nesse último conceito, várias classificações foram propostas, sendo a mais citada na literatura a de Praetorius et al.(21). Estes dividiram a forma cística em três variantes: unicística simples, produtora de odontoma e proliferante ameloblastomatosa. A forma neoplásica foi denominada tumor dentinogênico de células fantasmas ${ }^{(11,13,21)}$. Mas, além destas, outras classificações 
foram sugeridas, como as de Buchner ${ }^{(2)}$ e as de Hong et $a l^{(8)}$.

\section{Expressão das proteínas da MEC nas células fantasma}

As células fantasmas são pré-requisitos necessários para o diagnóstico de $\mathrm{COC}$, apesar de não serem patognomônicas destas lesões. Existe grande controvérsia em relação à natureza das células fantasmas. Alguns autores acreditam que elas possam representar ceratinização normal ou atípica ${ }^{(8,23,27)}$ ou o produto de matriz abortiva de esmalte em epitélio odontogênico ${ }^{(15,24,29)}$.

Em todos os casos de $\mathrm{COC}$ estudados neste trabalho observou-se que as células fantasmas exibiram forte reatividade para a fibronectina. Para o colágeno I foi verificada marcação mais fraca que para a fibronectina, sendo mais expressiva quando as células fantasmas se fusionavam, formando extensos aglomerados compactos. Tal fato também foi observado em relação à tenascina, cuja marcação foi mais fraca que para as outras duas proteínas.

Estudos ultra-estruturais têm demonstrado resíduos mitocondriais e retículo endoplasmático espalhados entre os filamentos de citoqueratinas em células fantasmas. A degeneração dessas estruturas membranosas liberaria ácidos graxos, os quais atrairiam íons cálcio; por esse mecanismo, parece provável que as células fantasmas se tornem calcificadas. Isso representaria uma verdadeira calcificação distrófica ${ }^{(9)}$, definida simplesmente como uma mineralização que ocorre em outros tecidos que não ossos e dentes, na ausência de um distúrbio mineral sistêmico ${ }^{(34)}$.

Em outro estudo ultra-estrutural(26) foram observados no citoplasma das células fantasmas feixes de tonofilamentos arranjados em várias direções e um considerável número de vesículas distribuídas entre estes, contendo cristais semelhantes a agulhas, considerados sítios de calcificação inicial nessas células. Tais vesículas apresentam semelhanças morfológicas com as vesículas de matriz observadas tanto na ossificação endocondral e intramembranosa normal, como também desempenhando um papel importante em outros sítios de calcificação ectópicos e patológicos, como válvulas aórticas humanas e cartilagem epifisária de ratos raquíticos. Desses achados, sugere-se que essas vesículas estão profundamente envolvidas no processo de calcificação nas células fantasmas do COC. Essas calcificações ectópicas são também observadas em tecidos mesenquimais, havendo poucos relatos de calcificação epitelial ectópica.

A formação e a maturação dos cristais de apatita biológicos estão sob o controle da matriz extracelular. Um dos papéis das proteínas específicas dos cristais é o controle da nucleação e do crescimento de apatita biológica durante o processo de mineralização, de acordo com Daculsi et al.(4). Estes demonstraram, através de estudos ultra-estruturais, o importante papel da fibronectina na nucleação precoce dos cristais, sugerindo, ainda, que tal processo deva ter um importante significado biológico na calcificação ectópica e na nucleação primária de tecidos calcificados.

Um dos determinantes do fenótipo celular é a MEC, e, em estudo realizado por Watson et al. ${ }^{(35)}$, ficou demonstrado que a matriz produzida por células que estão se mineralizando rapidamente continha uma quantidade de colágeno I e fibronectina três vezes maior que aquela secretada pelos clones de células que não estavam se mineralizando. Daí, sugere-se que o colágeno I e a fibronectina são críticos na formação de estruturas calcificadas, sendo os componentes predominantes na matriz produzida pelas células mineralizantes.

Baseando-se nas observações dos autores anteriormente citados, propõe-se que a marcação para a fibronectina e o colágeno I observada nas células fantasmas, principalmente nas áreas onde há fusionamento destas, provavelmente se relaciona com o processo de calcificação das células fantasmas, fenômeno este amplamente observado nos COCs.

\section{Expressão da fibronectina}

A fibronectina desempenha um importante papel estrutural e funcional na organização da MEC, além de suas importantes propriedades adesivas na morfogênese dental e na diferenciação celular. Na odontogênese, a fibronectina está envolvida nas interações célula-matriz as quais induzem o fenômeno de polarização de células a ela conectadas $^{(31)}$. Os achados aqui observados revelaram que a fibronectina estava distribuída pela MEC tanto na matriz intersticial como na membrana basal, verificando-se, na grande maioria dos casos, uma maior intensificação na interface epitélio-mesênquima, com um padrão de distribuição predominantemente contínuo e forte. Esse achado pode estar relacionado ao fenômeno de polarização das células da camada basal verificado nos casos onde houve tal tipo de imunomarcação. Em relação a isso, Oliveira ${ }^{(19)}$, em um estudo utilizando fibronectina em ceratocistos, cistos dentígeros e cistos radiculares, observou que nos primeiros a fibronectina expressou-se como uma linha contínua e mais intensamente marcada que nos outros. Isso sugere que tanto a elevada atividade fibroblástica na cápsula desses cistos como a polarização das células da camada basal, 
verificada de forma tão exuberante nesse cisto, podem estar envolvidos com esse achado.

Medeiros $^{(14)}$ também associou a forte imunorreatividade da fibronectina na membrana basal dos ameloblastomas plexiformes e foliculares à polarização das células periféricas. Entretanto, o padrão desmoplásico não exibiu essa imunorreatividade, e o autor sugere que isso possivelmente aconteça pela falta de polarização das células ameloblásticas periféricas em tal variante do tumor.

Em um dos COCs com proliferação ameloblastomatosa observaram-se áreas de degeneração cística, onde se verificou delimitação pela expressão linear de fibronectina, provavelmente em função da degeneração estromal. Essa marcação representaria, na verdade, a membrana basal.

Em um dos casos de COC produtor de odontoma houve marcação intra-epitelial de fibronectina. Lukinmaa e Walti$\mathrm{mo}^{(12)}$ e Santos e Sousa ${ }^{(25)}$ relataram achados semelhantes em relação à expressão da fibronectina do componente epitelial de germes dentários e lesões de origem odontogênica. Heikinheimo et al. ${ }^{(6)}$ demonstraram que, em alguns tumores odontogênicos, a fibronectina era produzida localmente pelas células tumorais. Portanto, a expressão intra-epitelial da fibronectina no COC observada neste estudo poderia ser assim justificada.

\section{Expressão da tenascina}

Segundo Chiquet-Ehrisnamn et al. ${ }^{(3)}$, Thesleff, Partanen, Vainio ${ }^{(31)}$ e Natali(18), a tenascina é uma glicoproteína da MEC que exibe uma maior expressão em ambientes instáveis, como nas migrações celulares, em especial nas células provenientes da crista neural, em áreas ativas de interações epitélio-mesenquimais e em estromas de neoplasias.

Nos casos de COC unicísticos e produtores de odontoma, observou-se uma marcação de aspecto variável para a tenascina, mas, de forma geral, essa expressão foi evidenciada com maior freqüência no conjuntivo junto à interface epitélio-mesênquima, ora contínua e forte, ora descontínua e fraca. A expressão da tenascina observada na cápsula dos COCs unicísticos foi fraca e focal, e apenas um COC produtor de odontoma exibiu imunomarcação. Lukinmaa et al. ${ }^{(13)}$ avaliaram a expressão da tenascina em COCs e germes dentários e também evidenciaram que a distribuição de tal proteína foi predominante no tecido conjuntivo, limitando o epitélio tumoral, e que os achados observados correspondiam ao verificado durante a odontogênese. Assim, os autores sugerem que o COC representa uma contraparte patológica da odontogênese normal.
Nos dois casos de COC com proliferação ameloblastomatosa não se observou marcação para a tenascina na interface epitélio-mesênquima, porém foi verificada marcação intra-epitelial nas áreas proliferativas. Como nestes casos há maior proliferação epitelial quando comparado aos casos não-proliferativos, fato comprovado em estudos utilizando marcadores de proliferação celular, como o antígeno nuclear de proliferação celular (PCNA) ${ }^{(5,30)}$ e Ki-67(5,36), esperava-se que houvesse reatividade para tal proteína na interface, dada sua relatada presença em áreas ativas de interação epitélio-mesênquima tanto no desenvolvimento dentário, quanto em tumores ${ }^{(17)}$. Isso nos leva a sugerir que, talvez, a interação com a cápsula não tenha grande influência nos casos de COC com proliferação ameloblastomatosa, como a observada para os ceratocistos odontogênicos, por Oliveira ${ }^{(19)}$. Este observou forte imunorreatividade para a tenascina na cápsula desse cisto, o que apontaria para uma marcante instabilidade tecidual desta cápsula e para a estreita relação entre tenascina e tecidos conjuntivos com elevados graus de migração e instabilidade. Hirshberg et al. ${ }^{(7)}$ já propuseram que a cápsula não representa apenas o suporte estrutural para a lesão, mas sim um fator em parte responsável e determinante pelo comportamento do cisto.

Já a presença da tenascina na interface epitélio-mesênquima nos COCs unicísticos suscitaria a importância dessa interação na formação da expansão cística. Em relação a isso, Hong et al. ${ }^{(8)}$ observaram que, quando a atividade proliferativa do epitélio excede a degeneração cística, o COC proliferativo é formado, e quando a degeneração cística prevalece, forma-se o COC não-proliferativo.

\section{Expressão do colágeno I}

Os diversos tipos de colágeno são componentes da MEC que garantem a integridade estrutural de tecidos e órgãos e conferem organização ao tecido conjuntivo. $\mathrm{O}$ colágeno do tipo I é mais polimerizado, agrupando-se em feixes espessos ${ }^{(28)}$ que são, provavelmente, responsáveis pela organização e pela maturação dos tecidos estromais de alguns tumores. Em nosso trabalho, todos os casos estudados exibiram marcação difusa e fraca na cápsula, não tendo sido encontrada nenhuma diferença entre os três tipos de COCs estudados.

\section{Conclusão}

De modo geral, verificamos neste trabalho que houve expressão variável das proteínas estudadas, tanto entre as 
lesões do mesmo grupo, como entre os três grupos. Não foi possível observar um padrão de marcação que denotasse diferenças entre os tipos unicístico simples, produtor de odontoma e com proliferação ameloblastomatosa. Esses achados reforçam a visão de que os vários tipos histológicos do COC podem representar simplesmente espectros histológicos diferentes de uma só entidade com comportamento biológico semelhante.

\section{Referências}

I. ABIKO, Y. et al. Immunohistochemical localization of amelogenin in human odontogenic tumors, using a polyclonal antibody against bovine amelogenin. Med Electron. Microsc, v. 34, n. 3, p. | 85-9, 200|.

2. BUCHNER, A. The central (intraosseous) calcifying odontogenic cyst: an analysis of 215 cases. J Oral Maxillofac Surg, v. 49, p. 330-9, | 991.

3. CHIQUET-EHRISNAMN, R.; HAGIOS, C.; SCHENK, S. The complexity in regulating the expression of tenascins. Bioessays, v. 17, n. 10, p. 873-8, 1996.

4. DACULSI, G. et al. Role of fibronectin during biological apatite crystal nucleation: ultra-estructural characterization. J Biomed Mater Res, v. 47, n. 2, p. 228-33, 1999.

5.FREGNANI,E.R. etal. Calcifying odontogenic cyst: clinicopathological features and immunohistochemical profile of ten cases. J Oral Pathol Med, v. 32, p. 163-70, 2003.

6. HEIKINHEIMO, K. et al. Distribution of extracellular matrix proteins in odontogenic tumors and developing teeth. Virchows Archiv A Cell Pathol, v. 61, p. I01-9, 1991.

7. HIRSHBERG, A et al. Collagen fibres in the wall of odontogenic keratocysts: a study with picrosirius red polarizing microscopy. J Oral Pathol Med, v. 28, p. 4I 0-2, 1999.

8. HONG, S.P.; ELLIS, G. L.; HARTMAN, K. S. Calcifying odontogenic cyst. A review of 92 cases with reevaluation of their nature as cysts or neoplasms, the natures of ghost cells, and subclassification. Oral Surg Oral Med Oral Pathol, v. 72, p. 56-64, 1991.

9.JOHNSON III,A. et al. Calcifying odontogenic cyst:a clinicopathologic study of 57 cases with immunohistochemical evaluation for cytokeratin. J Oral Maxillofac Surg, v. 55, p. 679-83, 1997.

I0. KRAMER, I. R:; PINDBORG, J.J.:SHEAR, M.The WHO histological typing of odontogenic tumours. A commentary on the second edition. Cancer, v. 70, n. I2, p. 2988-94, 1992.

I I. LU, Y. et al. Odontogenic ghost cell carcinoma: report of four new cases and review of the literature. J Oral Pathol Med, v. 28, n. 7, p. 323-9, 1999.

12. LUKINMAA, P. L.; WALTIMO, J. Immunohistochemical localization of types I, $\mathrm{V}$ and $\mathrm{VII}$ collagen in human permanent teeth and periodontal ligament. J Dent Res, v. 7I, n. 2, p. 39|-6, 1992.

13. LUKINMAA, P. L. et al. Features of odontogeneses and expression of cytokeratins and tenascin- $C$ in three cases of extraosseous and intraossseous calcifying odontogenic cyst. J Oral Pathol Med, v. 26, p. 265-72, 1997.

I4. MEDEIROS,A. M. Expressão da fibronectina, tenascina e colágeno I em ameloblastoma e no tumor odontogênico adenomatóide. 200 I. Tese (Doutorado em Patologia Oral) - Departamento de Odontologia, Universidade Federal do Rio Grande do Norte, Natal.

15. MOleri, A. B.; MOREIRA, L. C.; CARVALHO, J. J. Comparative morphology of seven new cases of calcifying odontogenic cysts. J Oral Maxillofac Surg, v. 60, p. 689-96, 2002.

16. MORI, M. et al. Immunohistochemical expression of amelogenins in odontogenic epithelial tumors and cysts. Virchows Arch A Pathol Anat, v. 418, p. 319-25, 1991.

17. NAGAI, N. et al. Immunohistochemical demonstration of tenascin and fibronectin in odontogenic and human fetal tooth germs. Eur J Cancer B Oral Oncol, v. 30, n. 3, p. 191-5, 1994.

18. NATALI, P. G. et al. Comparative analysis of the expression of the extracellular matrix protein tenascin in normal human fetal, adult and tumor tissues. Int J Cancer, v. 47, n. 6, p. 8||$-6,|99|$.

19. OliveIRA, M. D. C. Expressão de proteínas da matriz extracelular em cistos odontogênicos. 2000. Tese (Doutorado em Patologia Oral) - Departamento de Odontologia, Universidade Federal do Rio Grande do Norte, Natal.

20. ORSINI, G. et al. Peripheral calcifying odontogenic cyst. J Clin Periodontol, v. 29, p. 83-6, 2002.

21. PRAETORIUS, F. et al. Calcifying odontogenic cyst: range, variations and neoplastic potential. Acta Odontol Scand, v. 39, n. I, p. 227-40, 1981.

22. REGEZI, J. A. Odontogenic cysts, odontogenic tumors, fibroosseous, and giant cell lesions of the jaws. Mod Pathol, v. I5, n. 3, p. 33|-4I, 2002

23. REGEZI, J. A.; COURTNEY, R. M.; KERR, D. A. Keratinization in odontogenic tumors. Oral Surg Oral Med Oral Pathol, v. 39, n. 3, p. 447-55, 1975.

24. SAKU, T.; OKABE, H.; SHIMOKAWA, H. Immunohistochemical demonstration of enamel proteins in odontogenic tumors. J Oral Pathol Med, v. 2 I, p. I 13-9, 1992.

25. SANTOS, F. P.; SOUSA, S. C. M. Expressão da tenascina em tumores odontogênicos. RPG, v. 5, n. 4, p. 309, out/dez 1998. Resumos.

26. SATOMURA, K. et al. Initiation of ectopic epithelial calcification in a calcifying odontogenic cyst. J Oral Pathol Med, v. 28, p. 330-5, 1999.

27. SEDANO, H. O.; PINDBORG, J. J. Ghost cell epithelium in odontomas. J Oral Pathol, v. 4, p. 27-30, 1975.

28. SLAVKIN, H. C. Molecular determinants during dental morphogenesis and cytodifferentiation: a review.J Craniofac Genet Dev Biol, v. II, n. 4, p. 338-49, 1991. 
29. TAKATA, T. et al. Ghost cells in calcifying odontogenic cyst express enamel-related proteins. Histochem J, v. 32, n. 4, p. 223-9, 2000.

30. TAKATA, T. et al. Proliferative activity of calcifying odontogenic cysts as evaluated by proliferating cell nuclear antigen labeling index. Pathol Int, v. 48, n. II, p. 877-8I, 1998.

3।.THESLEFF, I.; PARTANE,A. M.; VAINIO, S. Epithelial-mesenchymal interactions in tooth morphogenesis: the roles of extracellular matrix, growth factors and cell surface receptors. J Craniofac Genet Dev Biol, v. II, p. 229-37, 1991.

32. TOIDA, M. Proliferative activity and subtyping of calcifying odontogenic cyst. Pathol Int, v. 50, p. 8I-3, 2000.
33. TOIDA, M. So-called calcifying odontogenic cyst: review and discussion on the terminology and classification. J Oral Pathol Med, v. 27, p. 49-52, 1998.

34. WADA, T. et al. Calcification of vascular smooth muscle cell cultures inhibition by osteopontin. Circ Res, v. 84, p. 166-78, 1999.

35. Watson, K.E. et al. Fibronectin and collagen I matrixes promote calcification of vascular cells in vitro, whereas collagen IV matrix is inhibitory. Thromb Vasc Biol, v. I8, p. 1964-7I, 1998.

36. Yoshida, M. et al. Histopathological and immunohistochemical analysis of calcifying odontogenic cysts. J Oral Pathol Med, v. 30, p. $582-8,2001$.
Endereço para correspondência

Lélia Batista de Souza

Av. Senador Salgado Filho 1.787

CEP 59020-390 - Natal-RN

Tel.: (84) 215-4108

Fax: (84) 215-4138

e-mail: leliasouza@dod.ufrn.br 